Middle East Journal of Science(MEJS)

\title{
CHIRAL STATIONARY PHASES USED FOR ENANTIOMERIC RESOLUTION
} Ömer Erdoğan ${ }^{* 1}$, Giray Topal ${ }^{2}$

${ }^{1}$ Adnan Menderes Üniversitesi, Fen Fakültesi, Kimya Bölümü, 09100, Aydın, Türkiye

${ }^{2}$ Dicle Üniversitesi, Fen Fakültesi, Kimya Bölümü, 21280, Diyarbakır, Türkiye

*omer.erdogan@adu.edu.tr

Enantiomer separation has attracted increasing attentions in pharmaceutical industry, due to great differences in pharmacological, toxicological and/or metabolic activities of enantiomeric drugs in living system. Several methods have been succesfully used to achieve chiral separation. To date the chromatographic method is one of the most effective. Numerous kinds of CSPS have been developed for chiral separation these include cyclo-dextrins, polysaccharides, macrocyclic antibiotics, ligand-exchange, Pirkle, crown ethers and protein derivatives. In this rewiev we will inform ligands and macromolecules used as CSP.

Key words: enantiomeric separation, chiral stationary phases. 


\title{
ENANTIYYMERİK REZOLÜSYON İÇİN KULLANILAN KİRAL SABİT FAZLAR
}

\begin{abstract}
Kiral ayırma, biyosistemlerde enantiyomerik ilaçların metabolik, toksikolojik ve farmakolojik olarak büyük farklllıklar göstermesinden dolay farmasötik endüstrinin artan ilgisini üzerine çekmektedir. Bu yüzden enantiyomerik ayrılmayı gerçekleştirmek için birçok metot başarılı şekilde kullanılmaktadır. Günümüzde kromatografik metot en etkili yöntemlerden biridir. Kiral ayırma için siklodekstrin, polisakkarit, makrosiklik antibiyotik, ligand-değişim, Pirkle, crown eter ve protein türevli birçok kiral sabit faz geliştirilmektedir. Bu derlemede, kiral sabit faz olarak kullanılan ligandlar ve makromoleküller hakkinda bilgi verilecektir.
\end{abstract}

Anahtar Kelimeler: enantiyomerik ayırma, kiral sabit fazlar

\section{Giriş}

1883 y1lında Lord Kelvin, yunanca el anlamındaki "cheir" kelimesinden kiralite kelimesini türetmiştir. Temel parçacıklardan insanlara kadar geniş yelpazedeki nesnelerin birçoğunda kiralite gözlemlenmiştir [25]. Bu gözlem sayesinde bilim insanları, evrenin oluşumunda kiralitenin önemli bir role ve gizeme sahip olduğunu öne sürmüşlerdir. Evrenimizde kiralitenin varlığı ile ilgili şu örnekleri verebiliriz. Eski mısır uygarlıklarındaki mezar odalarının duvarlarında kiraliteyi tasvir eden bazı resimler çizilmiştir. Ayrıca Carnegie Galaksi Atlasında yer alan 1168 galaksiden 540'ının, durgunluk hızlarının yönü ile karşılaştırıldığında kiral olduğu bulunmuştur [33]. Birçok asimetrik yapının bulunduğu bitki ve hayvanlarda, kiralitenin etkisi belirgindir. Bitki ve hayvanlardaki sarmal yapılar onları asimetrik yapar. Kısaca, kiralite evrenimizin neredeyse her yerinde vardır.

Kiral bileşiklerin iki önemli özelliği, onları akiral bileşiklerden ayırt eder. Birincisi düzlem polarize 1şığa karşı davranışları, ikincisi ise diğer kiral bileşiklerle etkileşimleridir. Bu iki özellikten faydalanarak değişik kromatografik (HPLC, Liquid Kromatografisi ve Clay Kolon Kromatografisi) yöntemler ile kiral bileşiklerin enantiyomerlerine ayrılması literatürde bilinmektedir [4,7,38,48,50]. Ayrıca Kapiler Elektroforez yöntemiyle de söz konusu ayırma işlemleri yapılmaktadır.

Enantiyomerik saflığı yüksek farmasötikler ilaç sanayinde oldukça yaygın kullanım alanı bulurlar [1]. Bu nedenle kiral bileşiklerin hazırlanması ve analizi oldukça önemlidir. Kromatografik metotlarla enantiyomerik ayırma ne kadar yüksek enantiyomerik saflıkta yapılabilirse; uygulamada insan sağlı̆̆ına etkili bir tedavi gerçekleştirmek o denli başarılı olur. Çevre kimyası, ilaç sanayi ve klinik analizlerde her zaman yüksek enantiyomerik saflık istenir. Bu saflık olmazsa her açıdan istenmeyen durumlar yaşanabilir. Hatta sonu ölümle neticelenen durumlar oluşabilir [43]. Rasemik farmasötik bileşiklerin ayrılması için günümüzde değişik teknikler kullanılmaktadır. Bunlardan en çok uygulama alanı bulanı HPLC ve kapiler elektroforezdir [2]. HPLC' de proteinler silika jel üzerine farklı ara kollar yardımıyla bağlanarak bir CSP hazırlanır. Hazırlanan bu CSP çeşitli ebatlardaki HPLC kolona doldurularak, bu kolon üzerinden rasemik bileşiklerin enantiyomerik rezolüsyonu gerçekleştirilir. Bu kolonlar ticari yolla 
temin edilebildiği gibi araştırmacılar tarafından analitik amaçlı veya preparatif amaçlı da hazırlanabilirler $[11,47]$.

\section{Yöntem}

\subsection{Kiral Sabit Fazlar}

Kiral sabit fazlar kesinlik, hız, hassaslık ve tekrar kullanılabilirlik gibi parametreler göz önüne alındığında kiralite biliminin vazgeçilmezleri arasındadır. CSP'ler akiral katı bir destek maddesi üzerine kiral bir molekülün kimyasal bağlarla bağlanması sonucu elde edilirler ve enantiyomerik rezolüsyonda çok önemli bir yere sahiptirler. Analitik, biyokimya, ilaç ve çevre endüstrisinde kromatografi ile enantiyomerlerin kiral rezolüsyon çalışmaları genellikle CSP'ler üzerinden yürütülmektedir. CSP'ler genellikle HPLC'de kullanılan çelik kolonlara doldurulmaktadır. Fakat kapiler elektroforez ve ince tabaka kromatografisi için bazı kiral kılcallar ve ince tabakalarda da kullanıldıkları bilinmektedir. Kiral kolonlar ve kapiler dolgu maddeleri; polisakkaritler, siklodekstrinler, antibiyotikler, proteinler, Pirkle tip ligand değiştiriciler ve crown eterler gibi çeşitli kiral selektörler ile paketlenmektedir [47].

\subsubsection{Polisakkarit Temelli Kiral Sabit Fazlar}

Selüloz, amiloz ve kitin gibi polisakkaritler, yeryüzünde bol miktarda bulunan optikçe aktif polimerlerdir. Bu polisakkaritlerin asit klorürler ve izosiyanatlarla reaksiyonu sonucu oluşan ester ya da karbamatları kiral tanıma özelliğine sahiptir. Polisakkarit temelli CSP'ler, birçok kiral bileşiğin enantiyomerik rezolüsyonunda yaygın olarak kullanılmaktadır [6,12,34,39].

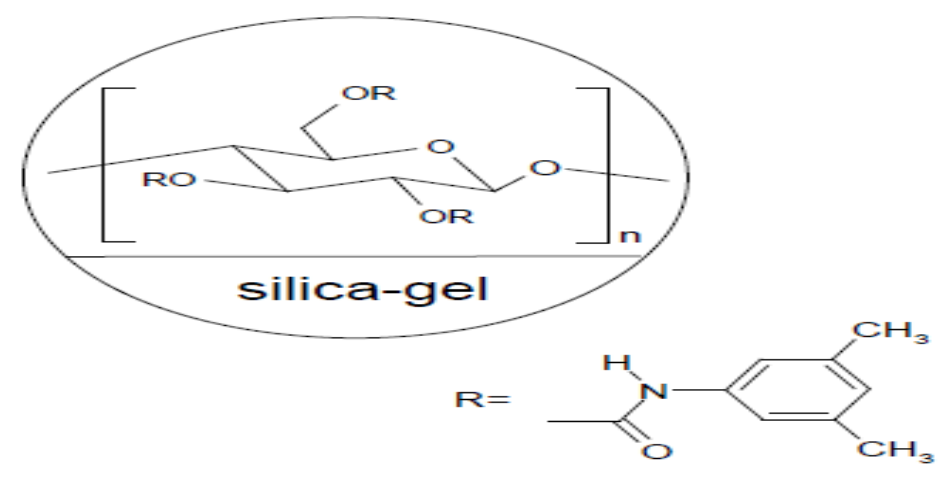

Şekil 2.1. Polisakkarit Temelli CSP'nin Yapısı

\subsubsection{Siklodekstrin Temelli Kiral Sabit Fazlar}

Siklodekstrinler D-(+)-glukopiranoz ünitelerinin $\alpha-(1,4)$ bağlarıyla bağlanması sonucu oluşan toroidal şekilli moleküllerdir. Siklodekstrinler "Bacillus macerans" bakterileri tarafından nişastanın sindirilmesiyle ya da siklodekstrin glikozilaz enzimi tarafından doğal olarak üretilirler. $\alpha-, \beta-$, ve $\gamma$ - 
siklodekstrinler doğada bol miktarda bulunmaktadır ve sırasıyla altı, yedi ve sekiz glukopiranoz birimlerinin bir araya gelmesiyle oluşmaktadırlar [3, 36].

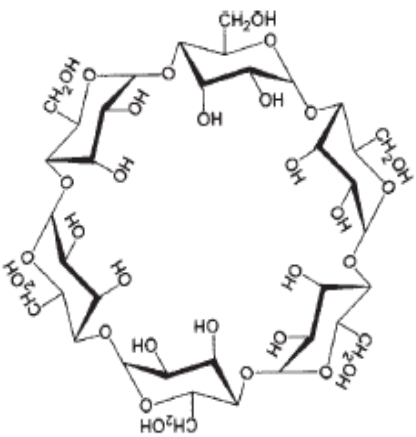

$\alpha$-siklodekstrin

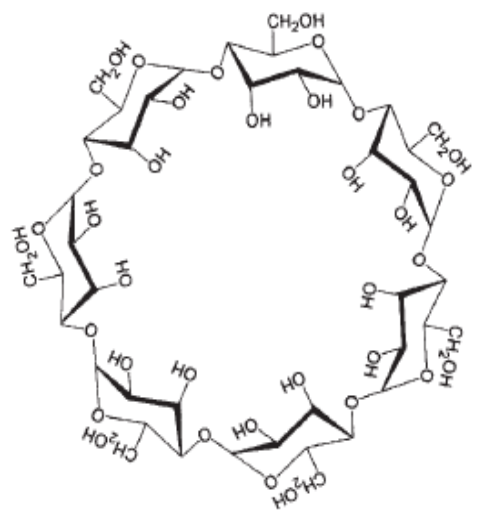

$\beta$-siklodekstrin

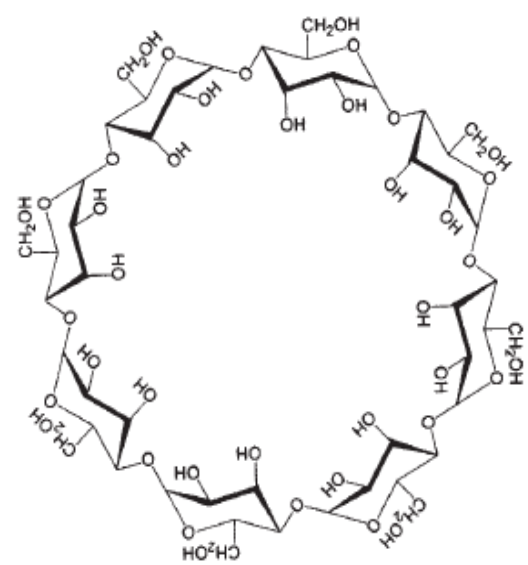

$\gamma$-Siklodesktrin

Şekil 2. $\alpha-$, $\beta$-, ve $\gamma$ - Siklodekstrinlerin Yapısı

$\mathrm{Bu}$ tür CSP'ler de vancomycin, ristocetin, teicoplanin v.b makrosiklik antibiyotikler kullanılmaktadır. İlk kullanılan antibiyotik 18 kiral merkez içeren vancomycin'dir. Vancomycin antibiyotiği, bakterinin hücre duvarındaki D-alanil-D-alanin grubuna bağlanarak bakterinin gelişimini durdurur. Bu bilgiden hareketle vancomycin ile hazırlanan CSP'de aminoasitlerin enantiyomerik rezolüsyonu denenmiş ve başarılı sonuçlar elde edilmiştir $[5,15,19]$.

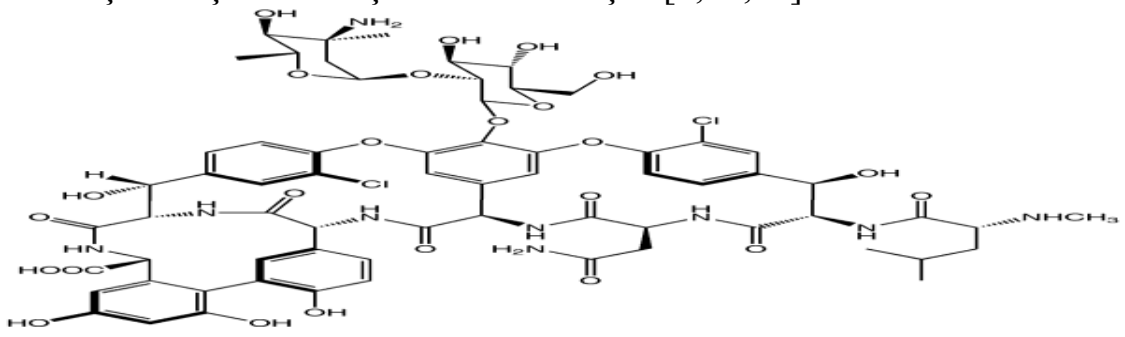

Şekil 3. Vancomycin Molekülünün Kimyasal Yapısı

\subsubsection{Pirkle Tip Kiral Sabit Fazlar}

Genellikle kiral sabit fazların tümü polimerik yapıda olan polisakkaritler ve proteinler, siklik yapıda olan siklodekstrinler ve crown eterler, kiral oyuk içeren antibiyotik temelli kiral sabit fazlar ve uygun ligand değiştiriler ile koordine edilmiş metal iyonlarını içeren ligand değişim fazları gibi bazı spesifik yapılara sahiptir. Bununla birlikte 1976'da Mikas ve çalışma grubu silikajele küçük bir kiral molekül tutturarak yeni bir CSP türüne zemin oluşturdular. Pirkle ve çalışma arkadaşları bu tip kiral sabit fazları geliştirerek, bu kolon dolgu materyallerinin Pirkle tip kiral sabit fazlar adı altında literatüre girmesini sağladılar [9,10,30,51]. 
Bu tip CSP'ler de, ya $\pi$-elektron alıcı grup ya $\pi$-elektron verici grup ya da her iki grubu birden içeren kiral bir molekül, iyonik veya kovalent bağlarla silika jele bağlanır. Bu yüzden Pirkle tip CSP’ler üç grupta sinıflandırılır( $\pi$-asidik, $\pi$-bazik, $\pi$-asidik-bazik). Kiral moleküllerdeki fenil grupları $\pi$-elektron verici eğilime sahiptir. Ancak elektronegatif atom ya da gruplar içeren fenil gruplarında $\pi$-elektron noksanlığı vardır ve bu gruplar yapıya $\pi$-elektron çekici bir özellik kazandırır $[13,38,40,41]$.

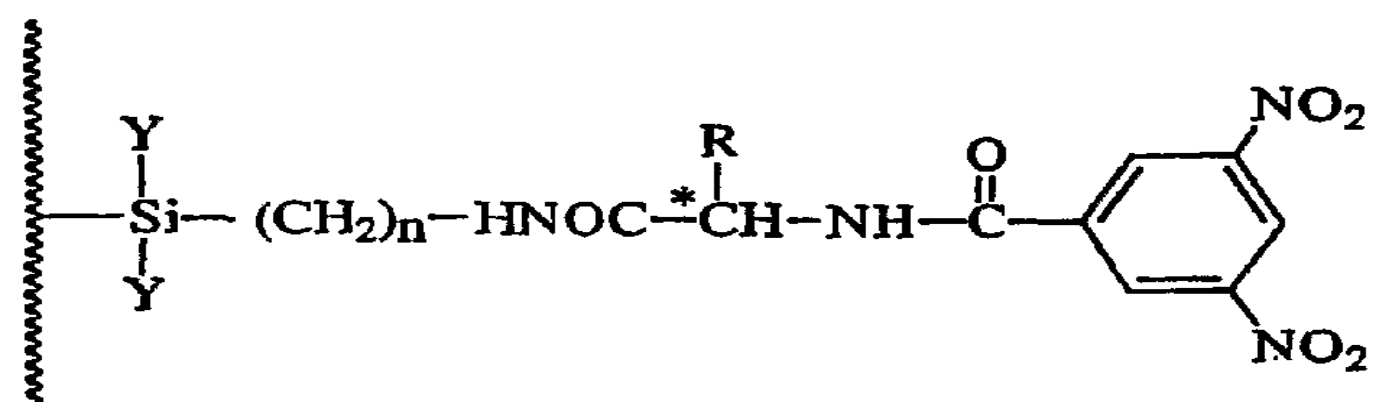

Şekil 4. Pirkle ve Arkadaşları Tarafından Hazırlanan Pirkle Tip CSP’ nin Yapısı

\subsubsection{Protein Temelli Kiral Sabit Fazlar}

Proteinler, glisin hariç kiral aminoasitlerden oluşan doğal polimerlerdir. Protein polimerler farklı moleküler arası bağlardan dolayı kıvrımlar içerir. Bu bağlar, protein molekülündeki kıvrımların oluklar oluşturmasını sağlar. Üç boyutlu kıvrımlı yapı proteine doğada enantiyoseçicilik kazandırır. Proteinlerle küçük moleküller arasında enantiyoseçici etkileşim en çok biyolojik sistemlerde gözlemlenir [17,18,20-22].

Proteinler enantiyoseçici özelliklerinden dolayı, kromatografi de CSP olarak kullanıma elverişli biyopolimerlerdir. Silika jel üzerine immobilize edilen proteinler HPLC'de birçok rasemik bileşiğin enantiyomerik rezolüsyonunda, başarılı sonuçlar vermiştir. Sıvı kromatografisinde kiral selektör olarak genelde bovine serum albumin(BSA), human serum albumin(HSA), rat serum albumin(RSA) ve guinea pig serum albumin(GPSA) proteinleri kullanılmaktadır. Bu proteinler içerisinde kiral ayırma kapasitesi en yüksek olan BSA ve HSA'dır. Bu proteinlerin yanı sıra glikoprotein temelli $\alpha$-asitglikoprotein, ovomucoid, avidin, tripsin ve enzim temelli kimotripsin, riboflavin, lizozim, pepsin, amiloglikosidaz proteinleri de kiral ayırmada kullanılmaktadır [23,24,26,32,37,46,49,52,53]. 


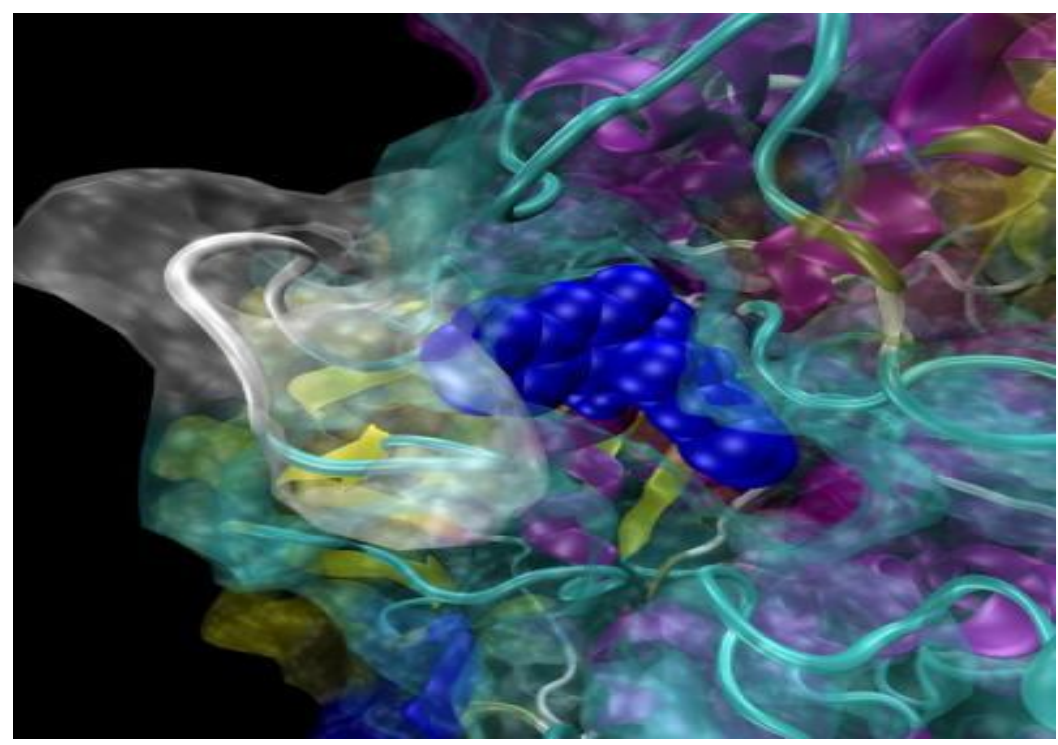

Şekil 2.5. Proteinin 3 Boyutlu Kiral Yapısı

\subsubsection{Bovine Serum Albumin(BSA)}

Bovine serum albumin sığıllardan elde edilen bir proteindir. Toplamda 607 tane aminoasit içeren, 66210 molekül kütlesine sahip bu, protein globuler yapıdadır. İzoelektrik noktası 4.7 olan bu protein asit özelliği gösterir ve suda çok iyi çözünür. Moleküler boyutu 141x42 Ao dür. BSA hidrofobik gruplar içeren birçok organik bileşik ile bağ yapabilme kapasitesine sahiptir. BSA, hidrofobik özellik gösteren inorganik anyonlarla da bağ yapabilmektedir. Yağ asitleri ile çok zayıf bağlar oluşturduğundan dolayı BSA kaprilik asit içerisinde stabilize edilmektedir [32,46,49,52,53].

\subsubsection{Human Serum Albumin(HSA)}

HSA insan kan plazmasında en bol miktarda bulunan proteindir. Karaciğerde üretilen HSA bovine serum albumin ile benzer özellikler göstermekte olup HSA'dan sonra sıvı kromatografisinde kiral selektör olarak en çok kullanılan proteinlerden biridir. Bu protein tek bir polipeptid zinciri üzerinde 580 aminoasit içerir ve molekül kütlesi 69000 'dir. Bu proteinin izoelektrik noktası 4.8 olup asidik özellik sergilemektedir [22].

\subsection{7 $\alpha 1$ - Asit Glikoprotein}

$\mathrm{Bu}$ protein orosomucoid olarak da literatüre edilmiş olup insan kan plazmasında bulunmaktadır. 141 aminoasit içeren $\alpha 1$ - asit glikoprotein 41000 molekül kütlesine sahiptir. 2.7 izolektrik noktasına sahip olan bu protein asidik özellik sergilemektedir. Bu protein 40 sialik asit kalıntısı içermektedir. Sialik asit kalıntıları nötral pH'lar da amonyum tipi bileşiklerle enantiyoseçici proseslere uygun bağ yaparlar [26]. 


\subsubsection{Ovomucoid}

Ovomucoid tavuk yumurtasının beyaz kısmından elde edilen bir glikoproteindir. 186 aminoasit içeren bu protein 55000 molekül kütlesine sahiptir. Toplam ağırlı̆̆ının $0,5-1 \%$ arasında sialik asit kalıntıları içerir. İzoelektrik noktası 4.5 olan ovomucoid asidik yapıdadır. Asit ve aminlerle bağ yapabilme kapasitesine sahiptir [23,53].

\subsubsection{Avidin}

Tavuk yumurtasının beyaz kısmından elde edilen diğer bir proteinde avidindir. 9.5-10 arasında izoelektrik noktasına sahip olan bu protein bazik özellik sergilemektedir. Avidin, her birinin molekül kütlesi 16400 olan dört özdeş alt birimden oluşmaktadır.17 tane asparagin aminoasidini içeren ve dört alt zincirden biri olan glikozidik zincir 1 mol biotin ile bağ yapabilmektedir. Nötral pH'lar da üzerindeki net pozitif yükten dolayı avidin anyonik örnekler için iyi bir enantiyoselektivite göstermektedir [22].

\subsubsection{Ovotransferrin}

Ovotransferrin tavuk yumurtasının beyaz kısmından elde edilen ve sıvı kromatografisinde kiral selektör olarak kullanılan bir proteindir. Bu protein daha çok demir, bakır, mangan, çinko v.b metal iyonlarıyla bağ yapar. İzoelektrik noktası 6.1-6.6 arasında olan bu protein 70000-78000 arasında bir molekül kütlesine sahiptir [22].

\subsubsection{Kimotripsin}

$\alpha$ - ve $\beta$ - olmak üzere iki formdan oluşan bu protein panreatik dokulardan elde edilmektedir. Kimotripsin'in $\alpha$-formu kromatografide kiral selektör olarak kullanılmaktadır. Molekül kütlesi 25000 ve izoelektrik noktası 8.1-8.6 arasındadır [22].

\subsubsection{Sellobiyohidrolaz-I}


Sellobiyohidrolaz-I, hayvanlardan elde edilen ve sıvı kromatografisinde selektör olarak en çok kullanılan glikoproteindir. 3.6 izoelektrik noktası sahip olan bu protein yine asit sınıfında yer almaktadır. Molekül kütlesi 60000’ dir [22].

\subsection{Kiral Crown Eter Temelli Kiral Sabit Fazlar}

Crown eterler yapılarında oksijen atomu ihtiva eden sentetik makrosiklik polieterlerdir. Oksijen atomu yerine azot ve kükürt atomu ihtiva eden Crown eterler de mevcuttur. Bu eterler sirasiyla aza Crown eterler ve tiyo Crown eterler olarak isimlendirilmektedir. Crown eterlere enantiyoseçici özellik kazandırmak için bu bileşiklere kiral bir grup bağlamak gerekir. Bu amaç için kullanılan en önemli kiral gruplar; binaftil, bifenantril, tartarik asit türevleri, aromatik bisiklo türevleri, tetrahidroindenoin v.b. dir $[14,27-29,31,42,44,45]$.

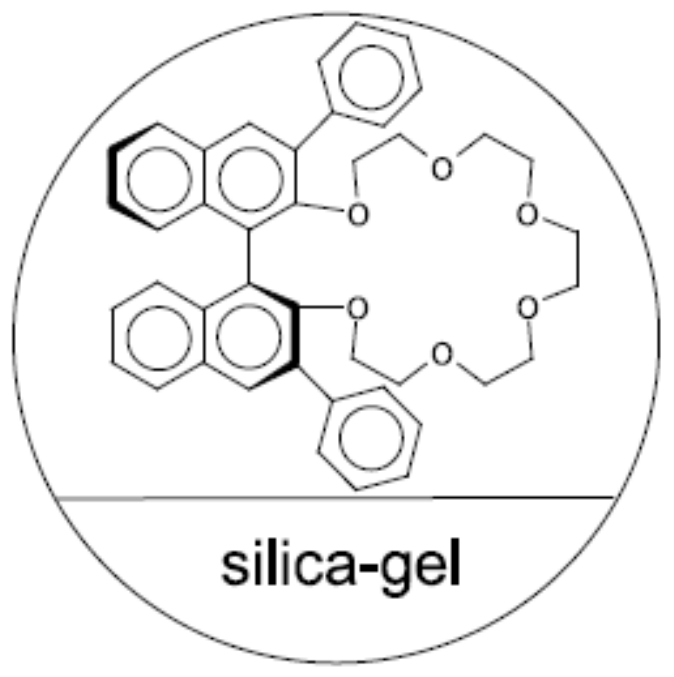

Şekil 6. Crown Eter Temelli CSP'nin Yapısı

\subsection{Kiral Ayırma Mekanizması}

Ligand değiştiriciler hariç, bütün kiral selektörlerde kiral tanıma mekanizması oldukça benzerdir. Bütün kiral selektörler enantiyomerler için kiral bir yüzey içerirler. Enantiyomerler bu kiral yüzeylere farklı bağ enerjisi ile bağlanarak geçici kompleksler oluştururlar. Enantiyomerlerin farklı stereokonfügrasyonları, kiral selektör yüzeyine farklı bağ enerjileriyle tutunmanın temel nedenidir. Geçici kompleksler bir seri etkileşim ile dengededir. Bu etkileşimler; hidrojen bağ1, $\pi$ - $\pi$ etkileşimleri, dipol-indüklenmiş dipol etkileşimi, iyonik etkileşimler ve sterik etkileşimlerdir. Ayrıca van der Waals ve yük değişim etkileşimleri gibi zayıf kuvvetler de kiral tanıma mekanizmasında temel rol oynar. Ligand değişim selektörlerinde kiral tanıma mekanizması diğer selektörlerden farklıdır. Bu selektörlerde bulunan metal iyonlarıyla enantiyomerler yer değiştirerek kiral ayırma sağlanır [16]. Kiral selektör yüzeyinde kiral tanıma mekanizması anahtar-kilit modeline göredir. Enantiyomerlerden biri kiral 
selektör yüzeyine uygun bir şekilde tutunurken; diğer enantiyomer tam olarak tutunmaz ve böylece enantiyomerik rezolüsyon gerçekleşmiş olur [25].

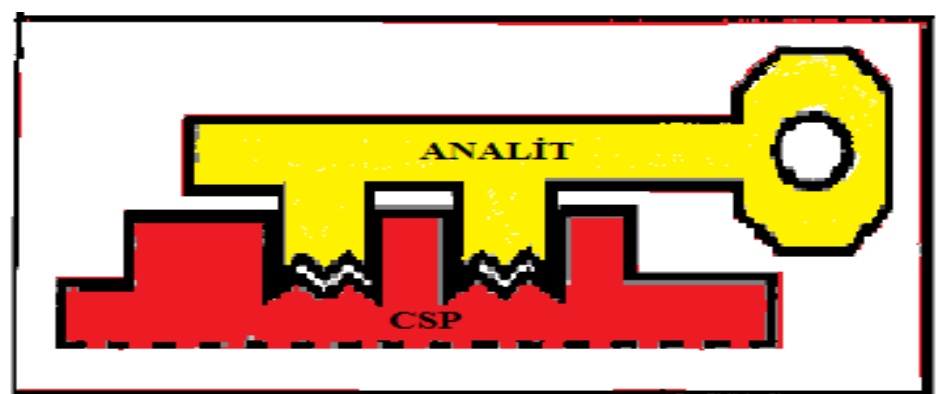

Şekil 7. Analit İle CSP Arasındaki Etkileşimin Anahtar-Kilit Modeliyle Şekilsel Gösterimi

\section{Sonuç}

$\mathrm{Bu}$ derleme kiral selektör olarak kullanılan ligandlar ve makromoleküller hakkında bilgi vermektedir. Kiral sabit fazlar arasında makrosiklik antibiyotik ve siklodekstrinlerden sonra en çok kullanılanı polisakkarit temelli CSP’lerdir. Günümüzde kiral selektör olarak kullanılmak üzere birçok molekül keşfedilmektedir. Ancak hız, tekrar kullanılabilirlik, hassaslık ve kesinlik gibi kromatografik parametrelere uygun veriler sağlamadığından bu kiral selektörlerin çoğu ticarileştirilememektedir. Kiroteknolojiye hesaplamalı kimya biliminin entegrasyonu ile bu sorunun aşılması umulmaktadır. 


\section{Kaynakça}

[1] Aboul-Enein, H. Y., \& Ali, I. (2003). Chiral separations by liquid chromatography and related technologies (Vol. 90): CRC Press.

[2] 2. Altria, K. D. (1996). Capillary electrophoresis guidebook: principles, operation, and applications (Vol. 52): Springer.

[3] 3. Armstrong, D. W., Chang, C.-d., \& Haing Lee, S. (1991). (R)-and (S)-Naphthylethylcarbamatesubstituted $\beta$-cyclo-dextrin bonded stationary phases for the reversed-phase liquid chromatographic separation of enantiomers. Journal of Chromatography A, 539, 83-90.

[4] 4. Bencini, A., Benelli, C., \& Gatteschi, D. (1984). The angular overlap model for the description of the paramagnetic properties of transition metal complexes. Coordination chemistry reviews, 60 , 131-169.

[5] 5. Berthod, A., Chen, X., Kullman, J. P., Armstrong, D. W., Gasparrini, F., D'Acquaric, I., Villani, C., \& Carotti, A. (2000). Role of the carbohydrate moieties in chiral recognition on teicoplaninbased LC stationary phases. Analytical chemistry, 72, 1767-1780.

[6] 6. Bezhan Chankvetadze. (2012). Recent developments on polysaccharide-based chiral stationary phases for liquid-phase separation of enantiomers. Journal of Chromatography A, 1269, 26-51

[7] 7. Bojarski, J., Aboul-Enein, H. Y., \& Ghanem, A. (2005). What's new in chromatographic enantioseparations. Current Analytical Chemistry, 1, 59-77.

[8] 8. Cabrera, K. (2004). Applications of silica-based monolithic HPLC columns. Journal of separation science, 27, 843-852.

[9] 9. Cakmak, R. (2008). PirkLe -tip kiral kolon kromotografisi yöntemiyle biyolojik öneme sahip kiral aminlerden $( \pm)-\beta$-metilfeniletilamin'in rezolüsyonu. Yüksek Lisans Tezi, Harran Üniversitesi.

[10] 10. Caude, M., Tambuté, A., \& Siret, L. (1991). Chiral stationary phases derived from tyrosine. Journal of Chromatography A, 550, 357-382.

[11] 11. Cavazzini, A., Pasti, L., Massi, A., Marchetti, N., \& Dondi, F. (2011). Recent applications in chiral high performance liquid chromatography: A review. Analytica Chimica Acta, 706, 205222.

[12] 12. Chankvetadze, B., Chankvetadze, L., Sidamonidze, S., Kasashima, E., Yashima, E., \& Okamoto, Y. (1997). 3-Fluoro-, 3-chloro- and 3-bromo-5-methylphenylcarbamates of cellulose and amylose as chiral stationary phases for high-performance liquid chromatographic enantioseparation. Journal of Chromatography A, 787, 67-77.

[13] 13. Chen, Z., Fuyumuro, T., Watabe, K., \& Hobo, T. (2004). Influence of spacers and organic modifiers on chromatographic behaviors on chiral diamide stationary phase with $\mathrm{N}-(3,5-$ dimethylbenzoyl)-D-phenylglycine. Analytica chimica acta, 518, 181-189.

[14] 14. Choi, H. J., Ha, H. J., Han, S. C., \& Hyun, M. H. (2008). Liquid chromatographic resolution of $\beta$-amino acids on CSPs based on optically active (3,3'-diphenyl-1,1'-binaphthyl)-20crown-6. Analytica Chimica Acta, 619, 122-128. 
[15] 15. D’Acquarica, I., Gasparrini, F., Misiti, D., Zappia, G., Cimarelli, C., Palmieri, G., Carotti, A., Cellamare, S., \& Villani, C. (2000). Application of a new chiral stationary phase containing the glycopeptide antibiotic A-40,926 in the direct chromatographic resolution of $\beta$-amino acids. Tetrahedron: Asymmetry, 11, 2375-2385.

[16] 16. Easson, L. H., \& Stedman, E. (1933). Studies on the relationship between chemical constitution and physiological action: Molecular dissymmetry and physiological activity. Biochemical Journal, 27, 1257.

[17] 17. Eriksson, B.-M., \& Wallin, A. (1995). Evaluation of the liquid-chromatographic resolution of indenoindolic racemic compounds on three protein-based chiral stationary phases. Journal of Pharmaceutical and Biomedical Analysis, 13, 551-561.

[18] 18. Fu, Y., Huang, T., Chen, B., Shen, J., Duan, X., Zhang, J., \& Li, W. (2013). Enantioselective resolution of chiral drugs using BSA functionalized magnetic nanoparticles. Separation and Purification Technology, 107, 11-18.

[19] 19. Guillaume, Y.-C., Ismaili, L., Truong, T.-T., Nicod, L., Millet, J., \& Thomassin, M. (2002). Chiral discrimination of phenoxypropionic acid herbicide enantiomers on teicoplanin phase: methanol dependence and eluent $\mathrm{pH}$ consideration. Talanta, 58, 951-959.

[20] 20. Haginaka, J. (2008). Recent progresses in protein-based chiral stationary phases for enantioseparations in liquid chromatography. Journal of Chromatography B, 875, 12-19.

[21] 21. Haginaka, J. (2012). 8.9 Chromatographic Separations and Analysis: Protein and Glycoprotein Stationary Phases. In E. M. Carreira \& H. Yamamoto (Eds.), Comprehensive Chirality (pp. 153-176). Amsterdam: Elsevier.

[22] 22. Haginaka, J. (2014). Chiral Separations: Protein Stationary Phases. In Reference Module in Chemistry, Molecular Sciences and Chemical Engineering: Elsevier.

[23] 23. Haginaka, J., Murashima, T., Fujima, H., \& Wada, H. (1993). Direct injection assay of drug enantiomers in serum on ovomucoid-bonded silica materials by liquid chromatography. Journal of Chromatography B: Biomedical Sciences and Applications, 620, 199-204.

[24] 24. Harada, K., Yuan, Q., Nakayama, M., \& Sugii, A. (1996). Effects of organic modifiers on the chiral recognition by different types of silica-immobilized bovine serum albumin. Journal of Chromatography A, 740, 207-213.

[25] 25. Hegstrom, R. A., \& Kondepudi, D. K. (1990). The handedness of the universe. Scientific American, 262, 108-115.

[26] 26. Hermansson, J. (1985). Resolution of racemic aminoalcohols ( $\beta$-blockers), amines and acids as enantiomeric derivatives using a chiral $\alpha$-1-acid glycoprotein column. Journal of Chromatography A, 325, 379-384.

[27] 27. Hyun, M. H. (2003). Characterization of liquid chromatographic chiral separation on chiral crown ether stationary phases. Journal of separation science, 26, 242-250. 
[28] 28. Hyun, M. H. (2012). 8.13 Chromatographic Separations and Analysis: Chiral Crown Ether-Based Chiral Stationary Phases. In E. M. Carreira \& H. Yamamoto (Eds.), Comprehensive Chirality (pp. 263-285). Amsterdam: Elsevier.

[29] 29. Hyun, M. H. (2016). Liquid chromatographic enantioseparations on crown-ether based chiral stationary phases. Journal of Chromatography A, 1467, 19-32.

[30] 30. Hyun, M. H., Cho, Y. J., Ryoo, J.-J., Jyung, K. K., \& Heo, G. S. (1995). Preparation and application of an (S)-naproxen chiral stationary phase. Journal of Chromatography A, 696, 173183.

[31] 31. Hyun, M. H., Tan, G., \& Xue, J. Y. (2005). Unusual resolution of N-(3,5-dinitrobenzoyl)$\alpha$-amino acids on a chiral stationary phase based on (+)-(18-crown-6)-2,3,11,12-tetracarboxylic acid. Journal of Chromatography A, 1097, 188-191.

[32] 32. Kiyohara, S., Nakamura, M., Saito, K., Sugita, K., \& Sugo, T. (1999). Binding of dltryptophan to BSA adsorbed in multilayers by polymer chains grafted onto a porous hollow-fiber membrane in a permeation mode. Journal of Membrane Science, 152, 143-149.

[33] 33. Kondepudi, D. K., \& Asakura, K. (2001). Chiral autocatalysis, spontaneous symmetry breaking, and stochastic behavior. Accounts of chemical research, 34, 946-954.

[34] 34. Kubota, T., Yamamoto, C., \& Okamoto, Y. (2004). Reversed-phase liquid chromatographic enantioseparation by cycloalkylcarboxylates of cellulose and amylose. Chirality, 16, 309-313.

[35] 35. Majors, R. E. (2006). Developments in HPLC column packing design. LC GC MagazineNorth America-Solutions for Separation Scientists, 29, 8-15.

[36] 36. Mitchell, C. R., \& Armstrong, D. W. (2004). Cyclodextrin-based chiral stationary phases for liquid chromatography. In Chiral Separations (pp. 61-112): Springer.

[37] 37. Narayanan, S. R. (1992). Immobilized proteins as chromatographic supports for chiral resolution. Journal of Pharmaceutical and Biomedical Analysis, 10, 251-262.

[38] 38. Nimura, N., \& Kinoshita, T. (1986). o-Phthalaldehyde-N-acetyl-L-cysteine as a chiral derivatization reagent for liquid chromatographic optical resolution of amino acid ernantiomers and its application to conventional amino acid analysis. Journal of Chromatography A, 352, 169177.

[39] 39. Ou, J., Lin, H., Tang, S., Zhang, Z., Dong, J., \& Zou, H. (2012). Hybrid monolithic columns coated with cellulose tris (3,5-dimethylphenyl-carbamate) for enantioseparations in capillary electrochromatography and capillary liquid chromatography. Journal of Chromatography A, 1269, 372-378.

[40] 40. Pirkle, W. H., \& Murray, P. G. (1996). Observations relevant to the differential intercalation of enantiomers between the strands of brush-type chiral stationary phases. Journal of Chromatography A, 719, 299-305.

[41] 41. Pirkle, W. H., Pochapsky, T. C., Mahler, G. S., \& Field, R. E. (1985). Chromatographic separation of the enantiomers of 2-carboalkoxyindolines and $\mathrm{N}$-aryl- $\alpha$-amino esters on chiral 
stationary phases derived from $\mathrm{N}$-(3,5-dinitrobenzoyl)- $\alpha$-amino acids. Journal of Chromatography A, 348, 89-96.

[42] 42. Qin, W., Xu, S., Xu, G., Xie, Q., Wang, C., \& Xu, Z. (2013). Preparation of silica gel bound crown ether and its extraction performance towards zirconium and hafnium. Chemical Engineering Journal, 225, 528-534.

[43] 43. Sheldon, R. A. (1993). Chirotechnology: industrial synthesis of optically active compounds: CRC press.

[44] 44. Shinbo, T., Yamaguchi, T., Nishimura, K., \& Sugiura, M. (1987). Chromatographic separation of racemic amino acids by use of chiral crown ether-coated reversed-phase packings. Journal of Chromatography A, 405, 145-153.

[45] 45. Steffeck, R. J., Zelechonok, Y., \& Gahm, K. H. (2002). Enantioselective separation of racemic secondary amines on a chiral crown ether-based liquid chromatography stationary phase. Journal of Chromatography A, 947, 301-305.

[46] 46. Stewart, K. K., \& Doherty, R. F. (1973). Resolution of DL-tryptophan by affinity chromatography on bovine-serum albumin-agarose columns. Proceedings of the National Academy of Sciences, 70, 2850-2852.

[47] 47. Tang, M., Zhang, J., Zhuang, S., \& Liu, W. (2012) Development of chiral stationary phases for high-performance liquid chromatographic separation. Trends İn Analytical Chemistry, 39, $180-194$

[48]

[49] 48. Van Gyseghem, E., Van Hemelryck, S., Daszykowski, M., Questier, F., Massart, D., \& Vander Heyden, Y. (2003). Determining orthogonal chromatographic systems prior to the development of methods to characterise impurities in drug substances. Journal of Chromatography A, 988, 77-93.

[50] 49. Wainer, I. W., \& Chu, Y.-Q. (1988). Use of mobile phase modifiers to alter retention and stereoselectivity on a bovine serum albumin high-performance liquid chromatographic chiral stationary phase. Journal of Chromatography A, 455, 316-322.

[51] 50. Yamagishi, A., Taniguchi, M., Imamura, Y., \& Sato, H. (1996). Clay column chromatography for optical resolution: selectivities of Lambda-[Ru (phen) 3] 2+ and Lambda-[Ru (bpy) 3] 2+ laponite columns towards 1, 1'-binaphthol. Applied clay science, 11, 1-10.

[52] 51. Yilmaz, H., Topal, G., Cakmak, R., \& Hosgoren, H. (2010). Resolution of ( \pm )- $\beta-$ methylphenylethylamine by a novel chiral stationary phase for Pirkle-type column chromatography. Chirality, 22, 252-257.

[53] 52. Zhang, Q., Zou, H., Wang, H., \& Ni, J. (2000). Synthesis of a silica-bonded bovine serum albumin s-triazine chiral stationary phase for high-performance liquid chromatographic resolution of enantiomers. Journal of Chromatography A, 866, 173-181. 
[54] 53. Zhou, L., Mao, B., \& Ge, Z. (2008). Comparative study of immobilized $\alpha 1$ acid glycoprotein and ovomucoid protein stationary phases for the enantiomeric separation of pharmaceutical compounds. Journal of pharmaceutical and biomedical analysis, 46, 898-906. 